\title{
Peran Orang Tua dalam Pendidikan Seks pada Anak Usia 5-9 Tahun Di Nagari Tanjuang Bungo Kecamatan Suliki Kabupaten Lima Puluh Kota
}

\author{
Mega Ade Nugrahmi*, Kartika Mariyona \\ Universitas Muhammadiyah Sumatera Barat \\ *Correspondence email: mega_gaulya@yahoo.com
}

\begin{abstract}
Abstrak. Pendidikan seks untuk anak usia dini bertujuan memberikan pengertian terhadap anak terkait alat reproduksinya, serta hal menyangkut perbandingan dua bagian alat reproduksi dan pengenalan organ tubuh secara dinamis yang bisa dimengerti si anak. Memberikan pendidikan seks adalah kewajiban orangtua untuk masa depan anak agar memproteksi diri dari apa yang telah menjadi martabat bagi seorang anak. Pendidikan seks sangat berguna karena menimbang banyak terjadinya kasus tindak kekerasan seksual kepada anak. Penelitian ini bertujuan menggali lebih dalam peran orang tua dalam pendidikan seks terhadap anak dalam memberikan informasi pendidikan seksual sesuai dengan kelompok usia anak untuk menekan tingginya angka pelecehan seksual kepada anak. Penelitian ini bersifat kualitatif, partisipan dipilih dengan teknik purposive sampling. Partisipan penelitian terdiri dari 4 orang, yaitu Walinagari Tanjuang Bungo, Kader, Orang Tua dan Anak. Teknik wawancara mendalam menggunakan alat perekam dengan panduan wawancara terstruktur, serta pencatatan dilapangan. Analisa data menggunakan qualitative content analysis dengan pendekatan collaizi. Peran orangtua di Nagari Tanjuang Bungo mengenai pendidikan seks pada anak dalam memperkenalkan, mengungkapkan, membagikan dan membimbing masih belum sempurna, karena ada faktor penghalang yaitu faktor pendidikan, faktor ekonomi dan sosial budaya dan faktor ekonomi keluarga, yang membuat orangtua sibuk dengan aktivitas pekerjaan sehari-hari untuk memenuhi nafkah keluarga. Akibatnya orang tua lupa akan hal perannya sebagai orang tua dalam mengenalkan pendidikan seks kepada anak sejak usia dini.
\end{abstract}

Kata kunci: Pendidikan Seks; Peran Orang Tua

Abstract. Sex education in early childhood aims for provide understanding to children regarding their reproductive organs, as well as matters concerning the differences between the two sexes and the introduction of dynamic body organs that the child can understand. Providing sex education is the obligation of parents for the future of their children to protect themselves from what has become the dignity of a child. Sex education is very useful because it considers the number of cases of sexual violence against children. This study aims to dig deeper into the role of parents in sex education for children in providing sexual education information according to the child's age group to reduce the high rate of sexual abuse to children. This research is qualitative, the participants are selected by purposive sampling technique. The research participants consisted of 4 people, namely Walinagari Tanjuang Bungo, Cadre, Parents and Children. The in-depth interview technique uses a recording device with a structured interview guide, as well as field notes. Data analysis used qualitative content analysis with collaizi approach. The role of parents in Nagari Tanjuang Bungo regarding sex education for children in introducing, expressing, sharing and guiding is still not perfect, because there are barrier factors, namely educational factors, economic and socio-cultural factors and family economic factors, which make parents busy with daily work activities. Days to provide for the family. As a result, parents forget about their role as parents in introducing sex education to children from an early age.

Keywords: Sex Education; The Role of Parents

\section{PENDAHULUAN}

Pendidikan seks pada anak tidak bermaksudi mendidik bagaimana cara melakukan seks secara dini,namun pendidikan seks pada anak menjelaskan tentang alat tubuh yang dimilik dan fungsinya, serta cara penyampaiannya diberikan secara perlahan dan bertahap, mulai dari mengenalkan tentang bagian atau organ reproduksi anak, mengenalkan perbedaan jenis kelamin, memisahkan tempat tidur anak, dan kemudian ajarkan cara menjaga aurat dan pandangan agar anak dapat menerima karunia dan pemberian dari Tuhan dengan baik. (Anwar, 2009)

Kejadian kekerasan seksual pada anak beberapa tahun ini sangat tinggi, faktanya data Organisasi Perserikatan Bangsa-Bangsa untuk anak UNICEF (2017) terdapat 176 juta anak di bawah umur 5 tahun di dunia. Kejadian kekerasan seksual di Indonesia dari data Komisi Perlindungan Anak Indonesia (KPAI) tahun 2015 terdapat 2.898 kasus di mana 59,3\% merupakan kekerasan seksual pada anak. Tahun 2016 terdapat 1000 kasus kekerasan seksual dan tahun 2017 terjadi peningkatan, yaitu sebanyak 2.737 kasus kekerasan terhadap anak, 52\% diantaranya merupakan kasus kekerasan seksual (KPAI, 2017).

Di Sumatera Barat tahun 2016 terdapat 108 kasus kekerasan seksual pada anak, 116 kasus di tahun 2017 dan 58 kasus di tahun 2018. Kasus ini terpencar di beberapa kota dan kabupaten dengan angka tertinggi yaitu Kota Padang, Kota Solok,Kota Bukittinggi, Kabupaten Agam dan Kabupaten 50 Kota (KPPPA, 
2018). Di Kabupeten 50 Kota tahun 2018 terdapat 9 kasus kekerasan seksual pada anak, 4 kasus terjadi di Situjuah Gadang, 2 kasus terjadi di Mudiak, 2 kasus lainnya terjadi didaerah Batuhampar serta 1 kasus lainnya terjadi di daerah Pangkalan (P2TP2A, 2018)

\section{METODE}

Penelitian ini bersifat deskriptif kualitatif untuk mendeskripsikan dan meringkaskan keadaan yang sesuai pada tujuan penelitian, melalui pendekatan studi kasus. Penelitian ini dilakukan pada bulan April-Juni 2021. Penelitian ini dilakukan di Nagari Tanjuang Bungo Kecamatan Suliki Kabupaten Lima Puluh Kota. Partisipan dipilih menggunakan teknik purposive sampling sebanyak 4 orang terdiri dari Walinagari Tanjuang Bungo, Kader, Orang Tua dan Anak.. Teknik wawancara mendalam diperlukan alat perekam dengan panduan wawancara terstandar, dan pencatatan dilapangan. Analisis data menggunakan qualitative content analysis dengan pendekatan collaizi. Validitas data dilakukan dengan dua cara yaitu: 1) triangulasi sumber dilakukan melalui wawancara kepada Walinagari Tanjuang Bungo,Kader, Orang Tua dan Anak dan 2) triangulasi data dengan cara mencari kesesuaian informasi dengan bermacam metode dan sumber informasi data. Selain dilakukan wawancara dan observasi, juga dilakukan observasi terlibat (participant obervation).

\section{HASIL DAN PEMBAHASAN}

Berdasarkan hasil wawancara mendalam tentang pendidikan seks terhadap anak pada 4 orang informan dikelompokkan pada tema sebagai berikut

\section{Peran Orang Tua Dalam Pendidikan Seks}

Kedua orangtua adalah guru pertama untuk anak, karena semua sikap, tata krama, tindakan,dan tutur bahasanya menjadi teladan. Sebagai orangtua perlu teliti dalam bersikap terhadap anaknya, agar si anak mendapatkan masa depan yang baik.

Berikut hasil wawancaranya:

\begin{abstract}
"Orang Tua sudah mengajarkan anaknya agar menutup aurat dan sudah mengenalkan bagian tubuh yang boleh disentuh atau tidak oleh orang atau teman berbeda jenis"(Informant III)
\end{abstract}

"Anak sudah mengetahui bagian tubuh mana yang boleh disentuh orang atau teman berbeda jenis,dan informasi tentang pendidikan seks ini si anak tau dari orang tua nya" (Informant IV)

\section{Faktor Yang Mempengaruhi Peran Orang Tua}

Peran orang tua sangat menentukan kepribadian seorang anak, karena masa perkembangan anak dimulai dari lingkungan keluarga, dipimpin dan didampingi oleh orangtua. Terdapat faktor yang dapat mendukung dan penghalang orang tua untuk memberikan pendidikan seks. Berikut hasil wawancaranya :

"Faktor pendidikan dan faktor ekonomi menjadi salah satu penghambat untuk menyampaikan informasi tentang pendidikan seks dan sewaktu menyampaikan informasi tentang seks si anak masih belum terbuka dan untuk mendengarkan kata-kata seks itu masih malu-malu. "(Informant 3)

\section{Peran Walinagari dan Kader dalam memberikan Pendidikan Seks}

Peran Walinagari dan Kader dalam mengatasi pelecehan seksual terhadap anak sangat antusias sekali untuk mencegah tingginya angka pelecehan seksua terhadap anak.

Berikut hasil wawancaranya:

\begin{abstract}
"Dalam kegiatan kenagarian tetap diberikan informasi tentang lingkup remaja khususnya pendidikan seksual ini karena dengan kondisi sekarang ini tidak menjadi hal yang awam lagi buat masyarakat untuk mencegah tingginya angka pelecehan seksual apalagi untuk anak- anak dan remaja."(Informant I)
\end{abstract}

"Dalam kegiatan yang dilakukan kader khususnya dalam kegiatan posyandu yaitu tetap memberikan informasi kepada masyarakat khusunya orang tua tentang pendidikan seks kepada anak" (Informant II)

\section{Diskusi}

Pendidikan mengenai seks sebenarnya merupakan kepedulian orang tua untuk nasib anak kedepan, untuk mempertahankan martabat si anak. "Sebagai orangtua harus teliti bersikap dalam mengerjakan sesuatu untuk anaknya, karena nasib dan martabat bangsa kedepan ada di tangan mereka dan nasib mereka disiapkan oleh orangtua saat ini (Anwar, 2009).

Berdasarkan hasil penelitian melalui wawancara terhadap 4 orang informant bahwa Pendidikan seks harus menjadi bentuk kepedulian orangtua terhadap nasib anak dalam menjaga martabat nya.

Orang tua berperan untuk menyampaikan pendidikan seks kepada anak melalui cara mengenalkan bagian/organ reproduksi anak dengan menggunakan bahasa yang santun dan mendidik, mengenalkan perbedaan antara organ reproduksi laki-laki dan perempuan, mengajari mereka membersihkan alat kelaminnya sendiri dan memisahkan tempat tidur anak. Hasil penelitian yang dilakukan oleh Masruroh (2019) menyebutkan untuk penyampaian informasi tentang pendidikan seks ini sudah disampaikan secara perlahan kepada anak, organ badan yang boleh diraba dan bagian tubuh yang tidak boleh diraba. Namun dalam penyampaian si anak malu-malu untuk mendengarkan penjelasan yang disampaikan. 


\section{SIMPULAN}

Pendidikan seks menjadi salah satu pengetahuan yang ilmunya tidak hanya membahas tentang banyak hal mengenai pelajaran seks. Pendidikan seks lebih kepada upaya menyampaikan informasi kepada anak tentang alat tubuh mereka, melihat perbedaan antara organ tubuh dan memberikan ilmu tentang anatomi tubuh secara mudah dan bisa di tangkap oleh si anak.

Faktor yang mempengaruhi peran orang tua untuk menyampaikan ilmu tentang seks terhadap anak, yaitu faktor pendidikan dan faktor ekonomi. Faktor diatas membuat orang tua lupa akan pentingnya peran orang tua dalam mengenalkan pendidikan seks kepada anak dan banyak orangtua yang beranggapan pendidikan seks terhadap anak belum layak untuk di berikan dan masih dianggap tabu.

\section{DAFTAR PUSTAKA}

Anwar dan Arsyad Ahmad, Pendidikan Anak Dini Usia "Panduan Praktis bagi Ibu dan Calon Ibu", Bandung: Alfabeta, 2009.

KPAI,2017. Jumlah Kasusu Kekerasan pada Anak. 2017

[Online]. www.kpai.go.id

Kementrian Pemberdayaan Perempuan Dan

Perlindungan Anak (KPPPA) Propinsi Sumatera Barat, 2018

Masruroh,Lailatul,2019 "Peran Orang Tua Dalam Pendidikan Seks Terhadap Anak Usia Dini Pada Keluarga Muslim Di Kampung Bina Karya Baru Kecamatan Putra Rumbia Kabupaten Lampung Tangah Tahun 2019" diunduh dari https//:resopitory.metrouniv.ac.id//skripsi

Pusat Pelayanan Terpadu Pemberdayaan Perempuan dan Anak (P2TP2A) Kabupaten Lima Puluh Kota Tahun 2018. Laporan jumlah kasus kekerasan seksual 3 tahun terakhir di Kabupaten Lima Puluh Kota .

UNICEF,2017. Jumlah Kekerasan Seksual Terhadap Anak di Dunia. 2017 [Online]. Availableat:http://www.radiopelitakasih.com/2017 /11/01/unicef-kekerasanpenganiayaan-seksualdan-pembunuhan-intai-jutaan-anak-di-dunia/ 